\title{
Cuando con andar no se anda: el verbo andar en la fraseología del español clásico. Una aportación a la lexicografía histórica*
}

\author{
ANA SERRADILLA CASTAÑO
}

Universidad Autónoma de Madrid

\section{PLANTEAMiENTO}

El objetivo de este estudio es ofrecer un panorama de las unidades fraseológicas que en español clásico incluyen el verbo andar. Se trata, pues, de hacer un recorrido por aquellas expresiones con andar cuyo significado figurado no es deducible de la suma de los significados de los elementos que las integran, y que presentan características tales como la pluriverbalidad, la institucionalización, la idiomaticidad, la alta frecuencia de uso, la fijación o la variación potencial (Corpas, 1997 y Montoro del Arco, 2006).

Para este análisis he partido de las expresiones que Covarrubias recoge en su Tesoro (1611): andar a la cordobana, andar a monte, andar a sombra de tejado, andarse a la flor del berro, andar de zocos en colodros... y, a continuación, he rastreado sus apariciones en otras obras lexicográficas y en documentos de la época que nos permitan conocer su proceso de formación, sus condiciones de uso, su vitalidad y su evolución en español. Para entender esta evolución se hace necesario, asimismo, profundizar en los valores que el verbo andar aporta a estas locuciones.

Desde épocas muy antiguas, se observa en español la presencia de andar en unidades fraseológicas; esto se debe a que este verbo tiene una gran capacidad para trasponerse metafóricamente (Serradilla, 2006 y 2011) y para pasar a tener, por tanto, un significado distinto al que el $D R A E$ presenta en su primera acepción: «Ir de un lugar a otro dando pasos» ${ }^{1}$. De hecho, llama la atención cómo en este diccionario, aparte de locuciones y otras expresiones, se incluyen hasta 19 acepciones para andar, muestra de sus muchas posibilidades semánticas. Tal y como señala Sánchez Jiménez:

* Este trabajo ha sido llevado a cabo en el marco del Proyecto de Investigación Diccionario electrónico multilingüe de verbos amplios de movimiento (FFI2012-33807), dirigido por Elena de Miguel. También ha sido parcialmente financiado por el Proyecto dirigido por Inés Fernández Ordóñez: Procesos de cambio en la sintaxis del español peninsular (FFI2012-31972). Una versión preliminar de este estudio se presentó en el VIII Congreso Internacional de la Sociedad Española de Historiografia Lingüística. Se trataba de una versión reducida que llevaba como título: «Andarse a la flor del berro: las unidades fraseológicas con el verbo andar en el Tesoro de Covarrubias». Agradezco a Santiago U. Sánchez Jiménez y a Jacinto González Cobas la lectura de este trabajo y sus interesantes sugerencias

${ }^{1}$ Este paso de movimiento real a movimiento figurado es general en los llamados verbos de movimiento en lenguas muy diferentes. Podríamos hablar así de una metáfora de carácter universal. 
Como verbo de desplazamiento, andar, en su significado más prototípico, expresa la actividad de un movimiento que tiene lugar en una trayectoria no delimitada y no orientada. En este ámbito se produce una especialización - ya fijada en el siglo $\mathrm{XVI}$ - de la manera como se desarrolla ese movimiento, fenómeno poco frecuente en las lenguas románicas, que tienden a incorporar en el lexema notas semánticas sobre la trayectoria (2011: 233-234).

El hecho de que el verbo indique un movimiento de trayectoria imperfecta o no delimitada es fundamental, en palabras de este mismo autor, «para dar cuenta de las traslaciones semánticas del verbo» (2011: 247) de las que me ocupo en este trabajo.

Así, aunque el verbo tiene un significado prototípico y en el propio lexema lleva implícito el tipo de desplazamiento ('dando pasos'), a lo largo de la historia ha sufrido una serie de evoluciones, reflejadas en las obras lexicográficas, que le permiten participar en construcciones para las que, en principio, con este único valor, no estaría capacitado. Es necesario, pues, acudir, a los valores originarios de andar y a su evolución para entender su participación en unidades fraseológicas en las que compite con otros verbos como ir (ir/andar a gatas) o estar (andarse/estar con las cuentas en la mano).

El que en muchas de las expresiones analizadas el verbo andar pueda sustituirse por ir se explica porque en español antiguo se registra el empleo de andar como verbo de movimiento de trayectoria orientada en competencia con ir. Dice al respecto Sánchez Jiménez:

En los inicios del idioma expresa, fundamentalmente, dos contenidos: movimiento ajustado a una trayectoria delimitada y orientada (compitiendo con ir) y movimiento desarrollado en una trayectoria no delimitada y no orientada. El enérgico empuje de ir provoca que el empleo de andar para la expresión de un movimiento de trayectoria orientada y delimitada se reduzca a algunos testimonios en esa etapa preliteraria [...]. Posteriormente, se produce en el marco del movimiento de trayectoria no delimitada una especialización semántica, que irá afianzándose como uso prototípico de andar, y que consiste en la incorporación de una nota semántica referida a la manera de movimiento ('dando pasos'). Esta precisión semántica supone la reducción de las clases léxicas que ocupan la posición de sujeto, limitadas a los animales que dan pasos y, al mismo tiempo, como efecto de nuestro conocimiento del mundo, la reducción del tipo de trayectorias que estos animales recorren (2011: 250-251).

Esta especialización, mencionada por el autor, es la que seguirá el verbo andar de manera generalizada en español, pero, como veremos a continuación, en algunas de las expresiones analizadas parece mantener el valor original ${ }^{2}$.

Por otra parte, el hecho de que en ocasiones pueda ser sustituido por estar posiblemente tenga que ver con la interpretación que hace Sánchez Jiménez del verbo como indicador de ubicación (2011: 253 y ss). No obstante, como este autor señala: «Por otro lado, ha de reconocerse que, dadas las características de andar, si el tema de ubicación -conforme a nuestro conocimiento del mundo- es dinámico [...], se conserva la noción de movimiento localizado en un espacio» (2011: 257). Lo que comparten andar y estar es, en fin, y sigo

\footnotetext{
${ }^{2}$ Obsérvese cómo en la edición de 1770 del Diccionario de autoridades se recoge este valor de 'ir', al que se califica de anticuado y que podría estar en la base de algunas de las locuciones analizadas.
} 
con palabras de este autor: «la falta de delimitación aspectual del evento, pero andar aporta un dinamismo continuo - heredado de su carácter como verbo de movimiento- que no puede expresar estar, de por sí, como palabra predicado» (2011: 266).

No es de extrañar, vistas las muchas posibilidades de este verbo, que en la primera edición del Diccionario de autoridades (1726) se recoja este comentario: «Es muchas veces verbo neutro, según las preposiciones, partículas, ó adverbios con que se junta». Veamos a continuación algunas de las locuciones en las que participa.

\section{CORPUS DE EXPRESIONES}

En un principio el corpus de expresiones analizadas está constituido por las unidades fraseológicas con andar recogidas por Covarrubias: andar a caza de grillos, andar a la bulla, andar a caza de gangas, andar a la cordobana, andar a monte, andar al retortero, andar a sombra de tejado, andar con el tiempo, andar con las cruces a cuestas, andar de camino, andar de Ceca en Meca, andar a Ceca y a Meca, andar de puerta en puerta, andar de venta en venta, andar de viga en viga, andar de zocos en colodros, andar en balanzas, andar (o estar) en cuentos, andar en golondros, andar en zuecos, andar entre la cruz y el agua bendita, andar la gata en el palomar, andar la loza, andar sobre la maroma, andarse a la flor del berro, andarse a sus anchuras, andarse de boda en boda.

Quiero llamar la atención sobre un aspecto que considero significativo: mientras que en el caso de ir o caer - por poner un par de ejemplos de verbos de movimiento que también participan en expresiones figuradas - las frases hechas se recogen en la entrada correspondiente a los verbos ir (ir a flux, ir a la parte, irse por su pie a la pila) y caer (caer de su burra, caer como moscas, caer en el lazo), en el caso de las UF con andar, estas no se recogen en la entrada del verbo, sino que hay que rastrear las expresiones en las entradas correspondientes al resto de elementos que acompañan a andar. Así, tenemos que acudir a balanzas, maroma, berro, boda, loza, tiempo, etc. Aunque después volveré a este punto, parece claro que Covarrubias no considera el verbo como un elemento central de la construcción, como ocurría en los otros casos mencionados, sino que es el resto de la locución el que aporta el significado a la unidad fraseológica y andar no es más que un verbo amplio de movimiento que, en ocasiones, no aporta una significación especial y que, incluso, podría cambiarse por otro.

Para tener una visión más completa del universo fraseológico existente en la época de Covarrubias, hemos de considerar también algunas otras locuciones que no recoge el autor pero que se documentaban ya en la época medieval y que, en algunos casos, continúan su andadura en el siglo XVII (Serradilla, 2011): andar a casa y monte, andar a gatas, andar a grillos, andar a rabo de borrega, andar a toma el cuerno, andar a vara, andar de boca en boca y andarse con las cuentas en la mano. Para completar el corpus, se deben incluir también algunas otras locuciones todavía hoy vigentes, que no se documentaban en la época medieval pero sí en fechas cercanas a la obra de Covarrubias: andarse por las ramas, andarse con tiento, 
andarse con rodeos, andar con pies de plomo... De todas ellas presentaré una mínima muestra. Comenzaré por aquellas que no aparecen recogidas por Covarrubias ${ }^{3}$ :

1. Amadís quedó en Gaula como oís, donde moró treze meses * y medio, en tanto qu'el rey Lisuarte tuvo el castillo del Lago Ferviente cercado, andando a casa y monte, que a esto más que a otras cosas era inclinado (1482-1492, Rodríguez de Montalvo, Garci: Amadís de Gaula, libros I y II).

2. Pelayo No con mis ojos. / Bras Ora sigue tus antojos, / que affición es que te ciega. / Tú sosiega. / no desmayes con dolores, / que tanbién yo, por amores, / ando a rabo de borrega (1497, Encina, Juan del: Representación sobre el poder del Amor).

3. Fray Pedro de Bobadilla, / no os hagáis sordo ni mudo, / que os tienen en esta villa / por muy famoso cornudo; / bien lo sabe el Provincial, / porque desde aqueste invierno / yo y el nuestro mayoral / andamos a toma el cuerno./ Fray Pedro Meléndez, cristiano, / mintió quien tal te dezía, / que el un cuarto es de marrano / y los tres de sodomía; / un fraile me dixo anoche / (el nombre del cual te niego), / que en el mesón de Pedroche / fuiste novio de don Diego (1465-1466, Anónimo: Coplas del Provincial).

Los ejemplos mostrados son las únicas documentaciones de estas expresiones que aparecen en CORDE. La siguiente locución no parece superar el primer tercio del siglo XVI:

4. E por sallir de so el mandado de su padre o madre, marido o parientes, vanse e creen aquellos que non solamente las mandan, más las farrean * como a bestias “¡Farre acá! ¡Farre acullá!”, después quel amor pasado —que dura quanto más un año e ya es mucho sy tanto dura- e de allý adelante ¡vía andar a vara! E todo esto por amor de aquel que en verdad non pierde sueño nin comer por ella (1438, Martínez de Toledo, Alfonso: Corbacho).

5. y aosadas que no se alaben de andar, como andan, a vara, * a lo que veo (1521, Anónimo: La Comedia Hipólita).

Andar de boca en boca es una locución frecuente en la época y se usa también en los siglos XVI y XVII con otros verbos: ir, crecer, llegar, volar, correr, subir... siempre con la idea de movimiento.

6. ¡Oh mi triste nombre y fama, cómo andas al tablero de boca en boca! ¡Oh mis secretos... (c1499-1502, Rojas, Fernando de: La Celestina. Tragicomedia de Calisto y Melibea).

7. Y de star los libros españoles escritos con descuido viene que casi todos los vocablos que la lengua castellana tiene de la latina, unos están corrompidos, qual más qual menos, y otros están mal usados; porque como no an andado escritos de personas dotas y curiosas en lo que avían de dezir, sino de mano en mano, o, por mejor dezir, de boca en boca su poco a poco se an ido corrompiendo (1535, Juan de Valdés: Diálogo de la lengua).

8. porque no dexa de cansar a vna persona andar de boca en boca (1610, Quevedo y Villegas, Francisco de: Sueño de la Muerte).

Obsérvese que en (7) también se usa andar de mano en mano, expresión que tampoco encontramos en la obra de Covarrubias. A continuación, vemos un uso figurado de una

\footnotetext{
${ }^{3}$ Todos los documentos presentados están extraídos del CORDE.
} 
expresión que sigue documentándose en época del autor pero que él no presenta más que con la variante ir a gatas «ir tendido por el suelo, como van el gato o la gata para cazar el ratón».

9. Pero hombre dificultoso (si no es culto, que es lo más probable) será adivinanza de carne y hueso o enigma en cuerpo y alma o alma y cuerpo penando en algún nudo gordiano, o materia y forma andando a gatas en algún problema de Aristóteles (1652, Domínguez Camargo, Hernando: Lucifer en romance de romance en tinieblas).

En los dos siguientes ejemplos observamos un uso figurado de una expresión que Covarrubias presenta con una variante: andar a caza de grillos ${ }^{4}$

10. Sabes sabes el modorro alla donde anda a grillos burlanle los mançebillos (c 1464-1474, Anónimo: Coplas de Mingo Revulgo).

11. Mal va a la zorra kuando anda a grillos mas peor la va kuando anda a los guevos. Kuando anda a grillos ai poko ke komer i mucha hanbre (1627, Correas, Gonzalo: Vocabulario de refranes y frases proverbiales).

Obsérvese, por otro lado, la variedad fraseológica con andar y estar, con que se presenta esta expresión, que tampoco recoge el autor del Tesoro:

12. La hermana, quando esto oyó, con grand ira respondió e dixo que ella tenía demonios, que usava vigardías; que ella, si mal hazía, que lo hazía de manera que todos lo sabían e que ella se andaba con las cuentas en la mano e con el diablo en el cuerpo e se echaba con el ombre bueno so color de ir e venir a penitencia ( $c 1400$ 1498, Anónimo: El baladro del sabio Merlín con sus profecías).

13. no hay muger mas virtuosa; porque siempre con las cuentas en la mano está la moza (c1667-c1680, León Merchante, Juan Manuel de: Carta 71).

Entre las expresiones que hoy perviven, algunas de las que no recoge Covarrubias se documentan, no obstante, en el español clásico ${ }^{5}$ :

14. el aire el águila o saeta, y tal vez anda con los pies de plomo. Pero, para la carga de un poeta, siempre... (1614, Cervantes Saavedra, Miguel de: Viaje del Parnaso $)^{6}$.

${ }^{4}$ Que define del siguiente modo: «perderle tiempo en procurar cosa, que pareciendo fácil de alcanzar se va de entre las manos y nunca se cumple nuestro deseo. El comendador griego pone este refrán: «Cuando la zorra anda a caza de grillos, no hay para ella ni para sus hijos». Hay una fábula de la zorra, que un día fue a caza de grillos; y cuando pensaba le tenía debajo de sí, sonaba en otra parte, y con esto anduvo perdida toda la noche, hasta que de cansada y corrida lo dejó, y dio ocasión al proverbio».

${ }_{5}^{5}$ Las locuciones andar como Pedro por su casa y andar manga por hombro, vigentes en la actualidad, no se documentan como tales pero sí con variantes formales: que assi paresce que ando como Pedro por demas (1570, Martínez de Castrillo, Francisco: Tratado breve sobre la maravillosa obra de la boca); se está juzgando que debéis de andar vagando como Pedro por de más (c1540-1579, Horozco, Sebastián de: Cancionero); sintió alborotado el bodegón, revuelto el palomar y las mujeres a manga por hombro, dando y tomando (1604, Alemán, Mateo: Segunda parte de la vida de Guzmán de Alfarache); déxenlo ansí, ansí lo hallan. Todo está manga por hombro, todo benga o todo baya (1580-a1627, Góngora y Argote, Luis de: Romances).

${ }^{6}$ Esta locución también aparece introducida por otros verbos: caminar, correr, tener, salir... 
15. e gran temeridad es, y muy insolente, que andemos con rodeos para alcançar lo que no podemos (1615, López, Diego: Declaración magistral sobre las emblemas de Andrés Alciato).

16. Dexémonos de "andar por las ramas"; mejor será dezirle claro lo que haze (1535-1536, Valdés, Juan de: Diálogo de la lengua) ${ }^{7}$.

17. por ti el refrán que dize que el hombre ande con tiento, y que la muger no la toque el viento (1534, Silva, Feliciano de: Segunda Celestina).

18. Vos, don Pascasio, siempre andáis con tiento. $1 .^{\circ}$ Que digáis que no doy es lo que siento (1663, Suárez de Deza, Vicente: Mojiganga de los casamientos) ${ }^{8}$.

Como he mostrado, hay expresiones de la época que no recoge Covarrubias. Se ha de decir que esto no hace desmerecer a este excelente diccionario ya que, obviamente, es imposible compendiar toda la inmensidad de una lengua y, por otro lado, no podemos perder de vista que estamos ante el primer gran diccionario de una lengua romance y el trabajo es mucho más que meritorio, teniendo en cuenta que no contaba con precedentes en los que apoyarse.

A continuación, propongo algunos ejemplos extraídos del CORDE de las unidades fraseológicas que sí aparecen en el Tesoro. Quiero llamar la atención sobre el hecho de que no todas ellas aparecen documentadas; así, no he encontrado datos ni en dicho corpus ni en el corpus de Davies de las siguientes unidades fraseológicas: andar a caza de grillos; andar a la bulla; andar a la cordobana; andar en golondros; andar en zuecos $\mathrm{y}$ andar la gata en el palomar. Esto puede tener que ver con que solo contamos con textos escritos y muchas de estas expresiones son más propias de la oralidad, sobre todo de registros coloquiales, que no siempre aparecen representados en la lengua escrita. Presento una muestra de las que sí aparecen documentadas en los corpus manejados:

19. Otros andan a caza de gangas, y se pierden presumiendo cazar algo, y pasado el día, llega la noche de la muerte, y se hallan burlados, las manos vacías de buenas obras (1636, Gómez de Tejada, Cosme: León prodigioso).

20. que en lo que le toca servir a Dios anda a monte y absente de sí y de lo que debe (c1610, San Juan Bautista de la Concepción: Juan La vida del justo como martirio).

21. Si bien en Castilla se holgaron muchos con la venida del Emperador, otros temían y andaban a sombra de tejado; porque los atrevimientos pasados cargaban sus

${ }^{7}$ Obsérvese que también se usa el verbo ir: Vanse muchos, o por las ramas de un inútil discurrir, o por las hojas (1647, Gracián, Baltasar: Oráculo manual y arte de prudencia). Aunque Covarrubias no define esta locución, sin embargo, sí la usa, por ejemplo, en la entrada de escribir: «que si se estudiase él solo, con luz de algunas glosas breves y ciertas, se sabría de raíz; y así todo es andar por las ramas, entretejiendo unas materias con otras, porque hablastes, como dicen, de escopetas».

${ }^{8}$ Otra expresión como andar a la pesca solo se observa en el siglo XVII con el significado literal:« a cada dueño de chalupa y pinaza que handan a la pesca de sardina, besugo, y otros géneros» (1631, Cano, Tomé: Diálogo entre un Bizcaýno y un Montañés). Téngase en cuenta que, como es lógico, el valor metafórico surge, en el caso de las locuciones analizadas, en un momento posterior al de su lectura literal. De hecho, en los textos de los primeros tiempos es este valor el que predomina y es necesario rastrear los casos de uso figurado. Véase Serradilla (2011) para la aparición de los primeros usos figurados de verbos de movimiento. 
conciencias, esperando y temiendo un riguroso castigo (1604-1618, Sandoval, Fray Prudencio de: Historia de la vida y hechos del Emperador Carlos V).

22. ¿si habló bien David diciendo que los malos andan al retortero por no decir alrededor? (1589, Pineda, Juan de: Diálogos familiares de la agricultura cristiana).

23. Agora no vamos a ganar beneficios, sino a holgarnos. El arancel sea que andemos con el tiempo, pues vos decís que Dios hizo el día para obrar y la noche para dormir y descansar (c1550, Arce de Otárola, Juan de: Coloquios de Palatino y Pinciano).

24. al pecador, que cada día anda con las cruces a cuestas de sus culpas y peccados (c1610- c1612, San Juan Bautista de la Concepción: Exhortaciones a la perseverancia).

25. lo uno porque ya el presidente andaba de camino para irse al casamiento de la hija (1638, Rodríguez Freile, Juan: El Carnero o Conquista y descubrimiento del Nuevo Reino de Granada).

26. Un hombre como vos, que vengáys a mendigar y andar de puerta en puerta: nunca Dios tal quiera (1553, Dueñas, Juan de: Espejo del pecador).

27. entender en la hacienda, dejándonos de andar de ceca en meca y de zoca en colodra, como dicen (1605, Cervantes Saavedra, Miguel de: El ingenioso hidalgo don Quijote de la Mancha $)^{9}$.

28. Que su hija Mariana anduvo algunos días de venta en venta perdida, y se quiso recoger en mi casa y mi mujer no osó por temor mío, y la recogió una vecina mía que se llama Ana Sabia y su marido Bartolomé, allí en el monte, en las casas de Figueroa, donde contó que sus padres se lo hacían hacer y no se lo guardaban, y que todo se lo comían, y que no osaba volver a casa, porque la alcahueta no había vuelto antes del día (c1605, Pasamonte, Jerónimo de: Vida y trabajos $)^{10}$

29. Desvanes quiero que habite / mujer de cincuenta arriba: / que es bien que viva en desvanes / quien anda de viga en viga. (1597-1645, Quevedo y Villegas, Francisco de: Poesías).

30. Muchos días ha que he andado en balanza sobre si me estaría bien o mal (1604, González, Gregorio: El guitón Onofre) ${ }^{11}$.

31. Por qué queréis, señora, que miremos / en vuestra presumçión y entonamientos, /y allá en conversaçión de vos burlemos? /¿Por qué raçón queréis andar en cuentos / por las yglesias, plaças y cantones, haçiéndonos de risa andar contentos? ( $c 1545$ 1575, Hurtado de Mendoza, Diego: Poemas) $)^{12}$.

${ }^{9}$ Obsérvese cómo aparece la expresión «como dicen», muestra de que ya se interpretaba como una locución. En este ejemplo vemos también una variante de andar de zocos en colodros. Asimismo, hay otros documentos con casos de variación fraseológica como el siguiente: «y después que ya estés harta de correr a ceca y meca, allá a los veinte y tres años» (1601, Lobo Lasso de la Vega, Gabriel: Manojuelo de romances).

${ }^{10}$ Se usa también con ir, venir, parar...

${ }^{11}$ Esta expresión se localiza con esta variante en singular o con otros verbos como estar o poner.

${ }^{12}$ No parece tener aquí el valor que indica Covarrubias. 
32. Pues ¿qué diremos del licenciado Juan Alvarez, sino que, como hombre bien temeroso y pavoroso, andaba entre dos aguas, y como dicen, entre la cruz y el agua bendi$t a$, porque el visorrey estaba muy mal con él desde los días atrás cuando llegaron a Panamá y por otras causas y razones que había muy legítimas? (1549-1603, Gutiérrez de Santa Clara, Pedro: Quinquenarios o Historia de las guerras civiles del Perú).

33. buena es la moza; y pues corre la edad, ande la loza. Aquí no hay quien lo atisbe ( $p 1615-a 1645$, Quevedo y Villegas, Francisco de: Bailes).

34. y parte por sofismas y trampas de los que andamos sobre la maroma, será menester que al fin ceda el Rey (1769, Azara, José Nicolás de: Cartas de Azara al ministro Roda en 1769).

35. y se andan, como dicen, á la flor del berro, desacordados de lo que está por venir (c1561, León, Fray Luis de: Exposición del Cantar de los Cantares) $)^{13}$.

36. Estuve en Valladolid algunos días que me andaba a la flor del berro. La mayor felicidad es no servir a ninguno; no conocía rey ni Roque, ni aun lo quería conocer. (1604, González, Gregorio: El guitón Onofre).

37. Escogí vida de aldea por andarme a mis anchuras, y para poder jugar a los cientos (1601, Lobo Lasso de la Vega, Gabriel: Manojuelo de romances).

38. Kien bien baila, de boda en boda se anda. (1627, Correas, Gonzalo: Vocabulario de refranes $y$ frases proverbiales).

39. si tengo de ser celosa de marido que cadal dia va de boda en boda festejando toda Valencia, (1561, Milán, Luis: El cortesano).

\section{DEFINICIONES DE LAS UNIDADES FRASEOLÓGICAS}

Dado que todas las expresiones analizadas no resultan transparentes para el hablante actual, dedicaré unas líneas a presentar sus definiciones ${ }^{14}$ :

andar a casa y a monte 'andar forajido'

andar a caza de gangas 'perder tiempo, pensando alcanzar alguna cosa que, cuando nos parece tenerla ya en las manos, se nos desbarata; como acontece al cazador, que yendo a tirar la ganga, le espera hasta que la tiene a tiro, y antes que dispare el arcabuz se le levanta, alejándose tan poco trecho que obliga a seguirla, y burlándole al segundo y al tercero tiro y a los demás, le trae perdido todo el día'

andar a caza de grillos 'perderle tiempo en procurar cosa, que pareciendo fácil de alcanzar se va de entre las manos y nunca se cumple nuestro deseo'

andar a gatas «Dicho de ponerse o andar una persona: Con pies y manos en el suelo, como los gatos y demás cuadrúpedos» $(D R A E)$

\footnotetext{
${ }^{13}$ Obsérvese cómo con el uso de «como dicen» se hace referencia a que ya en la época se es consciente de que estamos ante una unidad fraseológica.

${ }^{14}$ Uso comillas simples para recoger las definiciones de Covarrubias. Las comillas dobles implican que es una definición propia o que ha sido tomada de otro diccionario; en ese caso, se indica al lado el diccionario al que pertenece tal definición.
} 
andar a grillos «ocuparse en cosas inútiles o baladíes» $(D R A E)$

andar a la bulla 'andar a la revuelta'

andar a la cordobana '[hábito de andar desnudos algunos bellacos] habiéndose primero aforrado el estómago de muchos ajos crudos y vino puro'

andar a monte 'andar forajido'

andar a rabo de borrega 'andar a rastras, perezosamente'

andar a sombra de tejado 'andar retraído y recatado de la justicia'

andar al retortero 'andar a la redonda; díjose de tortera, una rodaja que las hilanderas ponen en el uso para cargarle, y díjose así, a torquendo, porque se va siempre torciendo a la redonda, de tortus, $a$, um $^{, 15}$

andar a toma el cuerno "ponerse los cuernos uno a otro, 16

andar a vara «dícese de la caballería que va entre las varas de un carruaje» (Dic. Aut.)

andar con el tiempo 'acomodarse'

andar con las cruces a cuestas 'andar en rogativas y plegarias, pidiendo con ellas al Señor, que se puso por nosotros en la cruz, nos conceda lo que le pedimos, siendo justo y conveniente a nuestra salvación y a honra y gloria suya'

andar con pies de plomo «[actuar] Despacio, con cautela y prudencia» (DRAE)

andar de boca en boca «Ser objeto de lo que hable o diga [alguien]; Saberse de público, estar divulgado [una noticia o un asunto]» (DRAE)

andar de boda en boda 'irse de fiesta en fiesta, de un convite a otro'

andar de camino 'aprestarse para hacer alguna jornada'

andar de Ceca en Meca / andar a Ceca y a Meca 'es ir vagando por el mundo como hacen los moros que van supersticiosamente a estos lugares como los cristianos que con mejor celo visitan a Roma, Hierusalem y Santiago'

andar de puerta en puerta 'ser pobre mendigo'

andar de venta en venta 'irse uno por esos caminos, comiendo y bebiendo y pidiendo limosna, como lo hacen muchos debajo de sombra de peregrinos'

andar de viga en viga 'suelen aplicar esto a las brujas, que, según algunos, toman varias formas de aves nocturnas, gatos y otros animales'

andar de zocos en colodros 'salir de un negocio peligroso y entrar en otro de mayor peligro'

andar en balanzas 'estar en una situación insegura, pudiendo decaer de su estado'

andar (o estar) en cuentos 'estar en peligro y sustentarse con artificio'

andar en golondros 'es andar uno desvanecido en vanidades, con esperanzas vanas y peligrosas; debe estar tomada la semejanza de los niños, que para sacar los golondrinos del nido, hacen invenciones, con que cayendo se descalabran'

\footnotetext{
${ }^{15}$ El DRAE presenta el valor figurado que ya existía en la época: «Andar sin sosiego de acá para allá».

${ }^{16}$ Este significado lo aporta Julio Rodríguez Puértolas en su edición Poesía crítica y satírica del siglo XV, Madrid, Castalia, 1989.
} 
andar en zuecos 'traer chapines muy altos, porque con ellos andan mal y desgraciadamente'.

andar entre la cruz y el agua bendita 'vivir con peligro y necesidad, de que huyáis de veros in extremis, andar en fin a peligro de muerte'

andar la gata en el palomar 'cuando hay alguna revolución del que entra en el cuarto de las mujeres a inquietarlas'

andar la loza 'Manera de hablar: ande la loza, cuando hacen mucho ruido las mozas holgándose unas con otras, a semejanza del que hacen los platos y las escudillas, cuando ellas mismas las lavan en los barreñones'

andar sobre la maroma 'es una galantería, que algunos hacen volteando sobre ella ${ }^{17}$

andarse a la flor del berro 'darse al vicio y la ociosidad, entreteniéndose en una parte y en otra'

andarse a sus anchuras 'vivir con libertad'

andarse con las cuentas en la mano 'ser beato, estar siempre rezando'

andarse con rodeos «evitar tratar un tema directamente» «detenerse en lo menos sustancial de un asunto, dejando lo más importante» $\left(D R A E^{18}\right)$

andarse con tiento 'actuar con cautela y prudencia'

andarse por las ramas «andarse por las márgenes» > «Detenerse en lo menos sustancial de un asunto, dejando lo más importante» (DRAE)

Estas locuciones siguen recogiéndose en diccionarios de épocas posteriores; incluso muchas de ellas siguen vigentes y, por tanto, se recogen en el DRAE. Propongo como muestra de su continuidad a lo largo de nuestra historia lingüística las definiciones que de algunas de estas unidades fraseológicas presenta el primer diccionario de la Academia (1726): andar a monte: «Lo mismo que esconderse,ó irse à ocultar al monte fugitivo y temeroso de la justicia, ù de otro peligro que le amenáza»; andar con el tiempo: «Conformarse con él y lo mas comun es tomarse à mala parte por el que lisònjéa, y sigue los dictámenes de el que puede, sin otra razón que contemplarle»; andar en balanzas: «ANDAR LA OPINION EN BALANZAS. Es no tener uno bien sentádo su crédito: que al modo que las balanzas suben y baxan, assi unos le tienen en buena reputacion, y otros por el contrario»; andar la loza: «ANDE LA LOZA. Phrase con que se dá à entender el bullicio y algazara que suele haver en algún concurso quando la gente está contenta y alegre»; andar sobre la maroma: andar en la maroma: «Además del sentído recto, metaphoricamente se dice de la persóna, ò persónas que andan en pretensiones, especialmente de Prebendas y Canonicátos de oficio, y de Beneficios curados, ù de Cáthedras : y tambien se suele decir de los sugétos que están mas avanzados, ò tienen mas juego y partído para conseguir y ocupar algun empleo, dignidád, ù oficio»; andarse a la flor del berro: «ANDAR A LA FLOR DEL BERRO, Lo mismo que andar à la briba, ù distraído, ANDAR. A LA BRIBA ES

${ }^{17}$ Como ya recogía en Serradilla (2006), aunque en esta definición no se menciona el significado figurado sí se avanza este en la siguiente explicación al referirse a los que observaban a los que estaban en la maroma: «tenían suspensos los ánimos [...] porque a cada vuelta pensaban que habían de precipitarse y dar consigo en la tierra». Estamos ante un precedente de expresiones como bailar / estar en la cuerda floja.

${ }^{18}$ Esta definición solo se da para «andarse por las márgenes». 
entregarse à la bribonería, y no querer trabajar»; andarse a sus anchuras: «Vivir con conveniencia y libertad, y desordenadamente»; andar a gatas: «Es caminar à quatro pies como arrastrando»; andar a grillos: «A los que andan en alguna negociación,que ni se espéra fruto,ni efecto, solémos decir que andan à grillos»; andar de boca en boca: «Es lo mismo que ser el objéto, ò asunto de la murmuración, ò conversation de todos»; andarse por las ramas: «Dexar en alguna acción, ù discurso lo cierto, sólido, è importante; y irse à lo insubstanciál y de ningun fundamento»; andar con pies de plomo: «Vale considerar despácio lo que se debe hacer, pensarlo bien, y executarlo con maduréz y discreción».

Terreros y Pando (1786), por su parte, recoge andar en balanzas como 'vacilar'; andar a monte como 'andar huido, ó perdido', andar a caza de grillos como 'perder el tiempo inutilmente'; andar a la flor del berro como 'briboncar, vagar'; andar en golondros como 'andar lleno de vanas, y peligrosas esperanzas' y andar a gatas lo presenta a través de traducciones: Fr. Aller á quatre sottes. Lat. Reptare.

Y Vicente Salvá (1837), solo por poner un ejemplo más, todavía recoge andar a la cordobana como una expresión ya anticuada: cordobana: $f$. Voz que se usaba en la frase ANDAR A LA CORDOBANA, que equivale á ANDAR EN CUEROS Ó DESNUDO. Nudum incedere.

A la vista de las definiciones lexicográficas, se puede afirmar que las expresiones analizadas siguen manteniendo el mismo valor que les otorgaba Covarrubias, salvo en un par de casos como andar en balanzas o la variante andar en la maroma ${ }^{19}$.

\section{VALORES DE $A N D A R$ EN LAS LOCUCIONES ANALIZADAS}

Como se puede observar, andar interviene con una frecuencia muy significativa en la composición de unidades fraseológicas; esto tiene que ver, como apuntaba al principio de este trabajo, con la capacidad de este verbo para trasponerse metafóricamente. Hay muchas realidades como la vida o el amor, por poner solo un par de ejemplos, que se interpretan como un camino que se anda. El movimiento en el espacio pasa a ser un movimiento figurado. Como señala Espinosa (2009: 161): «Podemos comprender mejor y, por tanto, razonar sobre dominios abstractos si partimos de lo que nos resulta próximo y más conocido» y por esta razón creamos unidades fraseológicas utilizando metáforas conceptuales en las que nos valemos de verbos como este muy frecuentes en nuestra lengua y con un significado, en principio, muy evidente para todos los hablantes.

Si tenemos en cuenta los posibles valores que el verbo andar puede aportar a estas locuciones, podríamos clasificarlas de la siguiente manera:

1. Locuciones con valor modal, es decir, expresiones que reflejan la manera de movimiento: andar a gatas, andar a la bulla, andar a la cordobana, andar a rabo de borrega, andar al retortero, andar con el tiempo, andar con las cruces a cuestas, andar con pies de plomo, andar en balanzas, andar (o estar) en cuentos, andar en golondros andar en zuecos, andar entre la cruz y el agua bendita,

\footnotetext{
${ }^{19}$ Para profundizar en el estudio de la presencia de la fraseología en algunas de las primeras obras lexicográficas, conviene acudir a Martínez Egido y Ruiz Gurillo (2006) y a Martínez Montoro (2001).
} 
andarse a la flor del berro, andarse a sus anchuras, andarse con las cuentas en la mano, andarse con tiento, andarse con rodeos, andarse por las ramas.

2. Locuciones con valor direccional, que indican un lugar o una actividad (es decir, que inciden en la orientación del movimiento): andar de boda en boda, andar de Ceca en Meca, andar a Ceca y a Meca, andar de puerta en puerta, andar de venta en venta, andar de viga en viga, andar la gata en el palomar, andar sobre la maroma; andar a casa y a monte, andar a monte, andar a caza de grillos, andar a caza de gangas, andar a grillos, andar a sombra de tejado, andar a toma el cuerno, andar a vara, andar de boca en boca, andar de camino, andar de zocos en colodros, andar la loza ${ }^{20}$.

Téngase en cuenta que andar, como se ha señalado anteriormente, lleva implícita la idea de manera de movimiento, pero también podía indicar una trayectoria orientada.

De todas formas, hay que considerar también que en las unidades fraseológicas analizadas el verbo andar tiene un peso diferente; en este sentido convendría distinguir entre los casos en los que existe un movimiento real (ir o andar) y aquellos en los que el movimiento no es tal:

1. Entre los primeros se incluyen las siguientes expresiones: andar a gatas, andar a rabo de borrega, andar a vara, andarse de boda en boda, andar de camino, andar de Ceca en Meca, andar a Ceca y a Meca, andar de puerta en puerta, andar de venta en venta, andar de viga en viga, andar de zocos en colodros, andar en zuecos, andar la gata en el palomar ${ }^{21}$, andar sobre la maroma.

2. Entre los segundos, es decir, entre aquellos en los que la locución no implica un movimiento real del agente, sino un movimiento figurado, se incluyen las siguientes expresiones: andar a casa y monte, andar a caza de grillos, andar a ca$z a$ de gangas, andar a grillos, andar a la bulla, andar a la cordobana, andar a monte, andar a sombra de tejado, andar a toma el cuerno, andar al retortero, andar de boca en boca, andar con el tiempo, andar con las cruces a cuestas, andarse con las cuentas en la mano, andar en balanzas, andar (o estar) en cuentos, andar en golondros, andar entre la cruz y el agua bendita, andar la loza, andarse a la flor del berro, andarse a sus anchuras, andarse por las ramas, andarse con tiento, andarse con rodeos o andar con pies de plomo.

Obsérvese que, en todo caso, el movimiento expresado en estas locuciones no implica necesariamente 'ir de un lado a otro dando pasos'; así, aunque en ocasiones pervive, como hemos podido ver, la idea de movimiento, se ha perdido la noción de que este movimiento deba realizarse con los pies.

Asimismo, para llegar a comprender mejor el proceso de formación de estas unidades, creo que se hace necesario indicar los casos en los que es el verbo el que aporta el

${ }^{20}$ Agradezco a Santiago U. Sánchez sus observaciones sobre esta posible clasificación de las unidades fraseológicas con verbos de movimiento.

${ }^{21}$ Obsérvese que esta expresión puede presentar una ambigüedad en su valor en tanto que puede indicar una ubicación aproximada o un movimiento en un espacio acotado. 
significado metafórico y cuándo son los demás elementos los que lo aportan ${ }^{22}$. Así, en las unidades que estoy analizando se da un distinto grado desplazamiento semántico del verbo: en este sentido, he presentado ejemplos en los que andar continúa expresando una idea de movimiento y son los complementos los que proporcionan el carácter figurado a la expresión (andar a gatas, andar a grillos, andarse con las cuentas en la mano, andarse por las ramas, andar en balanzas, andarse con tiento...) [en estos casos el verbo se sustituye frecuentemente por otro verbo (ir a gatas, estar con las cuentas en la mano, irse por las ramas, estar en balanzas, ir con tiento...)], he proporcionado también casos en los que se percibe con mayor nitidez la metaforización del verbo pero sigue siendo deducible su valor por las unidades que componen la expresión (andar sobre la maroma, andar de camino, andar en zuecos, andar con el tiempo...) y, por último, he incluido ejemplos en los que la expresión es prácticamente opaca y el carácter metafórico es aportado claramente por la conjunción de los diversos componentes (andarse a la flor del berro, andar a rabo de borrega, andar a toma el cuerno, andar la loza...). No obstante esta clasificación, debemos ser conscientes de que se trata de una escala gradual y es difícil establecer compartimentos estancos ya que es posible el trasvase de las locuciones de un grupo a otro.

\section{5. ÁMBITO SOCIOLINGÜÍSTICO EN EL QUE APARECEN LAS EXPRESIONES METAFÓRICAS}

En principio, y como se ha comentado más arriba, muchas de estas expresiones pertenecen al ámbito más coloquial y no aparecen reflejadas con profusión en la lengua escrita; de hecho, en algunos casos los ejemplos mostrados son los únicos que se documentan en CORDE y en otros ni siquiera se ha podido encontrar un solo ejemplo (andar a caza de grillos ${ }^{23}$, andar a la bulla, andar a la cordobana ${ }^{24}$, andar en golondros $^{25}$, andar en zuecos ${ }^{26}$ y andar la gata en el palomar ${ }^{27}$ ). Dado, sin embargo, que son recogidos y definidos por Covarrubias, y que todavía aparecen en los diccionarios de los siglos XVIII y XIX debían de gozar de una relativa difusión en la época.

En todo caso, se hace difícil trazar el mapa sociolingüístico del uso de las unidades fraseológicas con andar en el español clásico; la razón es que se trata de expresiones

\footnotetext{
${ }^{22}$ Ya comenté que Covarrubias no incluye estas expresiones en la entrada de andar

${ }^{23}$ Sí aparece su variante andar a grillos.

${ }^{24}$ Que aparece recogida todavía por Salvá más de dos siglos después y que, curiosamente, se localiza todavía hoy en los múltiples traductores que circulan en Internet.

${ }^{25}$ Se usa con este significado en el siguiente ejemplo: «Este, pues, doctoranduncio amaneció con golondros de doctor, una mañana que se le alteró el meollo» (1580-a1627, Góngora y Argote, Luis de: Romances).

${ }^{26}$ El siguiente ejemplo del Decamerón es el único encontrado: Este desdichado me abandona para, con su deshonestidad andar en zuecos por lo seco; y yo me las arreglaré para llevar a otro en barco por lo lluvioso.

${ }^{27}$ Esta expresión estaba, sin embargo, claramente asentada en la lengua; obsérvese el siguiente ejemplo de Sebastián de Horozco, con una variante formal, que aparece en su Teatro universal de proverbios: «Cuando tras alguno andamos / deseosos de querellalle, / tras su rastro siempre vamos / y donde entra le espiamos / para mejor apañalle. / Y cuando salto de mata / no puede encerrado dar, / decimos cuando no cata: / "iSus, que dentro está la gata, / metida en el palomar”».
} 
asimiladas por los hablantes que se encuentran en documentos de tradiciones discursivas muy variadas.

Es habitual encontrar estas expresiones en textos que pretenden reflejar la lengua hablada, como es el caso de El Corbacho, La Celestina, El diálogo de la lengua, La segunda Celestina, Mojigangas o incluso en algunas obras de Quevedo de carácter burlesco (es el caso de expresiones como andar a vara, andar de boca en boca, andar de viga en viga, andar la loza, andarse por las ramas...).

Quiero insistir, no obstante, en que la aparición de estas expresiones no se reduce a estas tradiciones discursivas: las encontramos en textos en verso (andar a gatas, andar a grillos, andar a rabo de borrega, andar a toma el cuerno, andarse a sus anchuras) y en textos en prosa de diverso carácter: oratoria (andar al retortero, andarse con rodeos) histórica (andar con el tiempo, andar de camino, andar de puerta en puerta, andarse con las cuentas en la mano), política (andar a gatas, andar sobre la maroma) religiosa (andar a monte, andar al retortero) o narrativa (andar a casa y a monte, andar con pies de plomo, andar de boda en boda, andarse a la flor del berro, andarse a sus anchuras, andarse con tiento, andarse con las cuentas en la mano). También se recogen en diccionarios de proverbios y refranes (andar a grillos, andar la loza, andarse a la flor del berro). En fin, lo que podemos observar es que estas locuciones están plenamente integradas en el discurso de los hablantes y que no se limitan a un tipo de escrito concreto.

\section{REFLEXIONES FINALES}

Tras la presentación de las distintas locuciones y el análisis de sus valores y usos, es el momento de recapitular algunas de las ideas que se han vertido en este estudio. El hecho de que Covarrubias no incluya estas unidades fraseológicas bajo la entrada de andar nos dice mucho de la perspicacia de este autor, que es consciente de que en muchos de los casos, el significado de la expresión suele darlo el elemento nominal de la unidad fraseológica, mientras que el verbo, más que aportar un significado concreto, lo que proporciona es la idea de dinamismo, frente a construcciones de significado y forma similar pero con valor estativo como es el caso de las unidades introducidas por estar. En todo caso, no podemos olvidar que estamos ante la primera obra lexicográfica de una lengua romance y no existe aún un claro modelo de sistematización.

Por otra parte, hemos observado cómo andar, un verbo que en su significado prototípico lleva implícita la idea de movimiento sin trayectoria definida, en ocasiones se presenta como competidor de $i r$. Si bien, en principio, esta competencia habría terminado en una época muy anterior a la que estoy analizando, la realidad es que esta se mantiene en el caso de algunas unidades fraseológicas en las que el verbo sí parece definir su trayectoria y, en este sentido, es sustituible por $i r$.

También se ha comentado en este estudio que andar es un verbo de movimiento que incluye en su lexema información sobre el tipo de desplazamiento existente. Cuando se integra en una unidad fraseológica y adquiere, por tanto, un valor metafórico, esta información desaparece $\mathrm{y}$, aunque la expresión pueda seguir expresando cierto dina- 
mismo, ningún hablante, ante una expresión como andarse a la flor del berro, entenderá implícita la idea de que hay un desplazamiento en el que alguien 'dé pasos'.

Se ha intentado en este trabajo trazar también un panorama sociolingüístico del uso de estas locuciones en el español clásico y, ante los datos obtenidos del corpus manejado, se puede asegurar que, aunque hay una mayor abundancia de ellas en textos que presentan un registro más coloquial, no por ello dejan de aparecer en textos que pertenecen a tradiciones discursivas de carácter formal. En este sentido, se observa que ocurre lo mismo que en el español actual.

Es evidente que queda mucho por hacer en el estudio de la fraseología histórica ${ }^{28} \mathrm{y}$ más específicamente en el análisis de los valores que los verbos de movimiento aportan a las locuciones en las que se integran, pero en estas páginas he intentado mostrar, al menos, un esbozo del uso y los valores de algunas de las expresiones figuradas que incluyen el verbo andar en la época clásica y a las que Covarrubias ya dedicó un hueco en su trabajo.

\section{REFERENCIAS BIBLIOGRÁFICAS}

ACERo DURÁNTEZ, Isabel (2004): «El tratamiento de la fraseología española e italiana en un diccionario bilingüe del siglo XVII», en D. Corbella et al., eds., Nuevas aportaciones a la historiografia lingüistica, Madrid, Arco/Libros, 1, pp. 199-210.

CORPAS PASTOR, Gloria (1997): Manual de fraseología española, Madrid, Gredos.

COVARRUBIAS, Sebastián de (1611 [1995]): Tesoro de la lengua castellana o española, ed. de Felipe C.R. Maldonado, revisada por Manuel Camarero, Madrid, Castalia. DAviES,

Mark: www.corpusdelespanol.org.

ECHENIQUE, M. ${ }^{\text {a }}$ Teresa (2003): «Pautas para el estudio histórico de las unidades fraseológicas del español», en Homenaje al profesor J. J. Bustos Tovar, Madrid, Universidad Complutense, pp. 545-560.

y M. ${ }^{a}$ José Martínez AlCALde $\left(2003^{2}\right)$ : Diacronía y gramática histórica, Valencia, Tirant Lo Blanch.

ESPINOSA ElORZA, Rosa María (2009): «El cambio semántico», en Elena de Miguel, ed., Panorama de la lexicología, Barcelona, Ariel, pp. 159-188.

MARTíneZ AlCALDE, Ma José (2002): «Las unidades fraseológicas en el Diccionario de Terreros», Boletín de la Sociedad Española de Historiografia Lingüistica, 3, pp. 129-149.

MARTíNez EgIDO, J. J. y L. Ruiz GuRILlo (2006): «Las unidades fraseológicas en el inicio de la lexicografía española (1495-1620)», en J. L. Girón et al., eds., Actas del VI Congreso Internacional de Historia de la Lengua Española, Madrid, Arco/Libros, 2, pp. 1531-1544.

MARTíNeZ MONTORO, Jorge (2001): «La fraseología en los diccionarios del español anteriores al siglo XX», en M. A. Esparza et al., eds., Estudios de historiografia lingüistica, Hamburgo, Helmut Buske, 2, pp. 905-923.

${ }^{28}$ Aunque en los últimos años se le ha empezado a prestar especial atención como demuestran algunos trabajos publicados en la última década: Acero (2004), Echenique (2003), Echenique y Martínez Alcalde (2003), Martínez Alcalde (2002), Serradilla (2004, 2006, 2011, 2012 y en prensa) o Velando (2003, 2004). 
MONTORO DEL ARCO, Estebán Tomás (2006): Teoría fraseológica de las locuciones particulares, Frankfurt, Peter Lang.

REAL ACADEMIA ESPAÑOLA (1726): Diccionario de la lengua castellana, en que se explica el verdadero sentido de las voces, su naturaleza y calidad, con las phrases o modos de hablar, los proverbios o refranes, y otras cosas convenientes al uso de la lengua, Tomo primero, Madrid, Imprenta de Francisco del Hierro.

: Banco de datos (CORDE) [en línea]. Corpus diacrónico del español. $<\mathrm{http}: / /$ www.rae.es $>$ [octubre-diciembre de 2011].

(2001): Diccionario de la Real Academia Española, Madrid, Espasa.

SALVÁ, Vicente (1837): Diccionario de la lengua castellana por la Academia Española, Madrid.

SÁNCHEZ JIMÉNEZ, Santiago U. (2011): «Andanzas del verbo andar» en Carsten Sinner, José Luis Ramírez y María Jesús Torrens, eds., Tiempo y espacio y relaciones espaciotemporales desde la perspectiva de la lingüística histórica, San Millán de la Cogolla, Cilengua, pp. 233-269.

SERRADILLA CASTAÑo, Ana (2004): «Ir y caer como constituyentes de locuciones fraseológicas que no implican movimiento», Verba Hispánica, XII, pp. 131-141.

(2006): «Expresiones idiomáticas con verbos de movimiento en la historia del español: desde el siglo XVII hasta la actualidad», en Elena De Miguel, Ana Serradilla y Azucena Palacios, eds., Estructuras léxicas y estructuras del léxico, Frankfurt am Main, Peter Lang, pp. 73-93.

(2011): «Apuntes sobre fraseología histórica: las expresiones figuradas con verbos de movimiento en español medieval», CLAC, 45, pp. 21-54.

(2012): «Andarse a la flor del berro: las unidades fraseológicas con el verbo andar en el Tesoro de Covarrubias», en Elena Battaner Moro, Vicente Calvo Fernández y Palma Peña Jiménez, eds., Historiografía Lingüistica: líneas actuales de investigación, Münster, Nodus Publikationem, II, pp. 822-831.

(en prensa): «Unidades fraseológicas con verbos de movimiento en español medieval», Actas del XXVI Congreso Internacional de Lingüistica y Filología Románicas.

TERREROS Y PANDO, Esteban de (1786-1788): Diccionario castellano con las voces de ciencias y artes y sus correspondientes en las tres lenguas francesa, latina e italiana, Madrid, Viuda de Ibarra.

Velando Casanova, M. (2003): «Sobre las expresiones del tipo non vale un figo en lexicografía«, Res Diachronicae: Anuario de la AJIHLE, 2, pp. 405-413 [Edición en línea: http://home.pages.at/resdi /Numeros/Numero2/Parte1_Art44.pdf]

(2004): «Entre dientes: fijación de una unidad fraseológica», http://www.uji.es/bin/publ/edicions/jfi9/fang/6.pdf. 